\title{
Equivalent annual cost: a method for comparing the cost of multi-use medical devices
}

\author{
David R. Sinclair, MD
}

Received: 24 January 2010/Accepted: 11 February 2010/Published online: 2 March 2010

(C) Canadian Anesthesiologists' Society 2010

\section{To the Editor,}

Single-use and multi-use medical devices are used regularly in the practice of anesthesia. Single-use disposable infusion pumps are directly comparable with regard to cost. ${ }^{1}$ In previous cost-effectiveness studies, the costs of various multi-use programmable infusion pumps have been compared directly. ${ }^{2,3}$ However, the costs of multi-use infusion pumps are not directly comparable because they have distinct operating costs (delivery tubing, maintenance) and different lifetimes. To account for these features, the equivalent annual cost (EAC) of each pump should be calculated. The EAC represents the annual cost of owning and operating the pump over its entire lifetime. ${ }^{4}$ The EAC can be used as a decision-making tool in capital budgeting when comparing the annual costs of multi-use devices with unequal service-lives and operating costs, such as monitoring equipment or airway management devices. The EAC is based on the assumption that the device will be replaced indefinitely by an identical device at the end of its lifetime. The EAC does not take into account that the device will be used for less than its service life or upgraded during its use.

Consider the purchase of two pumps, Pump $\mathrm{A}_{\mathrm{A}}$ and Pump $_{\mathrm{B}}$, with identical functions, distinct operating costs, and different service-lives. In a cost-effectiveness analysis

D. R. Sinclair, MD ( $\square)$

University of Miami, Miami, FL, USA

e-mail: dsinclair@med.miami.edu of similar devices, one selection criterion is the cost of the devices. First, the present value (PV) of the cost of each pump is calculated to measure the cash flows over the lifetime of the pump as if the cash flows were made today (see Table 1). The EAC is based on the assumption that the pumps will generate the same annual costs in perpetuity. The pumps have an indefinite series of constant operating costs every year. The calculation of EAC takes into account this constant level of cash flow (annuity) by incorporating a present value interest factor of annuity (PVIFA) in its calculation (see Table 1). Also, the PVIFA can be obtained directly from an annuity table. ${ }^{4}$ To find the PVIFA, look for the row corresponding to the number of years $(t)$ and then find the column for the percentage (R). The number at the intersection of the row and column is the PVIFA. To calculate EAC, the PV of the costs for each pump is then divided by the PVIFA.

For example, suppose Pump $_{\mathrm{A}}$ 's purchase price is $\$ 5,000$; it costs $\$ 1,200$ per year to operate, and it must be replaced every five years. Pump $_{\mathrm{B}}$ 's purchase price is $\$ 4,000$; it costs $\$ 1,400$ per year to operate, and it must be replaced every seven years. If taxes are ignored and we assume a $7 \%$ rate of return, the annual costs can be determined (see Table 1). Since all dollar amounts represent an output of cash, they have a negative sign. Calculate the annuity factor (see Table 1). Since EACs are directly comparable, Pump $_{\mathrm{B}}$ should be purchased because it costs $\$ 903$ per year vs $\$ 1,428$ per year for Pump A $_{\mathrm{A}}$. The longer life and lower operating costs offset the higher

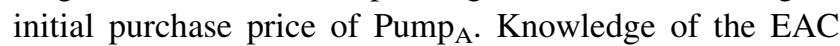
approach allows clinicians to make cost-effective decisions regarding similar devices using common capital investment formulas.

Competing interests None declared. 
Table 1 Summary of formulas and calculations

1. The PV of costs formula:

$\mathrm{PV}$ of costs $=\left[\mathrm{OC} /(1+\mathrm{R})^{\mathrm{t}}\right]-\mathrm{C}$

where $(\mathrm{R})$ is the discount rate or rate of return, $(t)$ is the expected lifetime of the pump, (C) is the initial cost of the pump, and (OC) is the estimate of annual operating costs (cost of maintenance and equipment)

Pump $_{\mathrm{A}}:$ PV $=-\$ 1,200 /(1.07)^{5}-\$ 5,000=-\$ 5,856$

Pump $_{\mathrm{B}}: \mathrm{PV}=-\$ 1,400 /(1.07)^{7}-\$ 4,000=-\$ 4,872$

2. The PVIFA formula:

PVIFA $=\left\{1-\left[1 /(1+\mathrm{R})^{\mathrm{t}}\right]\right\} / \mathrm{R}$

where $(\mathrm{R})$ is the rate of return and $(\mathrm{t})$ is the expected lifetime of the pump.

5 year annuity factor for Pump $\mathrm{P}_{\mathrm{A}}=\left\{1-\left[1 /(1.07)^{5}\right]\right\} / 0.07=4.10$

7 year annuity factor for $\operatorname{Pump}_{\mathrm{B}}=\left\{1-\left[1 /(1.07)^{7}\right]\right\} / 0.07=5.39$

3. The EAC formula:

$\mathrm{EAC}=(\mathrm{PV}$ of costs $) \times(\mathrm{PVIFA})$

$\mathrm{EAC}_{\mathrm{A}}=-\$ 5,856 / 4.10=-\$ 1,428$

$\mathrm{EAC}_{\mathrm{B}}=-\$ 4,872 / 5.39=-\$ 903$

$\mathrm{PV}=$ present value; $\mathrm{PVIFA}=$ present value interest factor of annuity; $\mathrm{EAC}=$ equivalent annual cost

\section{References}

1. Valente $M$, Aldrete JA. Comparison of accuracy and cost of disposable, nonmechanical pumps used for epidural infusions. Reg Anesth 1997; 22: 260-6.

2. Ilfeld BM, Morey TE, Enneking FK. Portable infusion pump used for continuous regional analgesia: delivery rate accuracy and consistency. Reg Anesth Pain Med 2003; 28: 424-32.

3. Ilfeld BM, Morey TE, Enneking FK. New portable infusion pumps: real advantages or just more of the same in a different package? Reg Anesth Pain Med 2004; 29: 371-6.

4. Ross SA, Westerfield RW, Jordan BD. Fundamentals of Corporate Finance, $8^{\text {th }}$ ed. New York, New York: McGraw Hill Irwin; 2008: 154-63, 325-6, A6-A7. 